\title{
Degradable gene delivery systems based on Pluronics-modified low-molecular-weight polyethylenimine: preparation, characterization, intracellular trafficking, and cellular distribution
}

\author{
This article was published in the following Dove Press journal: \\ International Journal of Nanomedicine \\ 23 February 2012 \\ Number of times this article has been viewed
}

\begin{abstract}
Wei Fan ${ }^{1,2, *}$
Xin $\mathrm{Wu}^{1, *}$

Baoyue Ding $3, *$

Jing Gao ${ }^{4}$

Zhen Cail

Wei Zhang'

Dongfeng Yin'

Xiang Wang'

Quangang Zhu'

Jiyong Liu'

Xueying Ding ${ }^{4}$

Shen Gao'

'Department of Pharmaceutics, Changhai Hospital, Second Military Medical University, Shanghai, ${ }^{2}$ Department of

Pharmaceutics, The 425th Hospital

of PLA, Sanya, ${ }^{3}$ Department of

Pharmaceutics, Medical College of

Jiaxing University, Jiaxing, ${ }^{4}$ Department

of Pharmaceutics, School of Pharmacy,

Second Military Medical University,

Shanghai, People's Republic of China

*These authors contributed equally to this work
\end{abstract}

Correspondence: Shen Gao

Department of Pharmaceutics, Changhai Hospital, Second Military Medical University,

Shanghai, People's Republic of China

Tel +862181873715

Fax +86 21 818737I5

Email liullk@I26.com

Xueying Ding

Department of Pharmaceutics,

School of Pharmacy, Second Military

Medical University, Shanghai,

People's Republic of China

Tel +862181871293

Fax +86 2I 8187 I293

Email dingxueying@126.com
Background: Cationic copolymers consisting of polycations linked to nonionic amphiphilic block polymers have been evaluated as nonviral gene delivery systems, and a large number of different polymers and copolymers of linear, branched, and dendrimeric architectures have been tested in terms of their suitability and efficacy for in vitro and in vivo transfection. However, the discovery of new potent materials still largely relies on empiric approaches rather than a rational design. The authors investigated the relationship between the polymers' structures and their biological performance, including DNA compaction, toxicity, transfection efficiency, and the effect of cellular uptake.

Methods: This article reports the synthesis and characterization of a series of cationic copolymers obtained by grafting polyethyleneimine with nonionic amphiphilic surfactant polyetherPluronic ${ }^{\circledR}$ consisting of hydrophilic ethylene oxide and hydrophobic propylene oxide blocks. Transgene expression, cytotoxicity, localization of plasmids, and cellular uptake of these copolymers were evaluated following in vitro transfection of HeLa cell lines with various individual components of the copolymers.

Results: Pluronics can exhibit biological activity including effects on enhancing DNA cellular uptake, nuclear translocation, and gene expression. The Pluronics with a higher hydrophiliclipophilic balance value lead to homogeneous distribution in the cytoplasm; those with a lower hydrophilic-lipophilic balance value prefer to localize in the nucleus.

Conclusion: This Pluronic-polyethyleneimine system may be worth exploring as components in the cationic copolymers as the DNA or small interfering RNA/microRNA delivery system in the near future.

Keywords: Pluronics, gene transfer, nonviral vectors, transfection efficiency, cellular uptake

\section{Introduction}

Gene therapy has become a promising strategy for the treatment of many inheritable or acquired diseases that are currently considered incurable. Because of their structural diversity, easy production, nonimmunogenicity, and safety, delivery of nucleic acids into cells using cationic polymers has recently attracted remarkable interest in the field of nonviral gene therapy. ${ }^{1,2}$ Polycation polyethylenimine (PEI) is one of the most effective and widely studied synthetic nonviral gene delivery vectors, and it has been employed for designing DNA delivery vehicles. ${ }^{3,4}$ Through the addition of cationic polymers to DNA, the condensed complexes are spontaneously formed through electrostatic interactions between the positively charged groups of the polycation and the negatively charged phosphate groups of the DNA, resulting in efficient transport of 
intact DNA into the nucleus. ${ }^{5-7}$ The whole gene delivery using PEI involves condensation of DNA into compact particles, uptake into cells, release from the endosomal compartment into the cytoplasm, and uptake of the DNA into the nucleus. The high transfection efficiency of PEI/DNA complexes has been ascribed to the capacity of PEI to buffer endosomes, which protects DNA from nuclease degradation and facilitates endosomal escape of PEI/DNA complexes (the "proton sponge" effect). ${ }^{8,9}$ However, polyplexes of PEI/DNA have shown low colloidal stability and considerable toxicity in vivo. ${ }^{10}$ Meanwhile, as both the transfection efficiency and cytotoxicity seem to depend on such physicochemical properties as molecular weight and branching ratio, it becomes evident that polymer structure significantly influences the efficacy of PEI-based vectors. ${ }^{9,11}$ Therefore, the discovery of new potent materials still largely relies on empiric approaches rather than a rational design.

Pluronic ${ }^{\circledR}$ block copolymers, which consist of hydrophilic ethylene oxide (EO) and hydrophobic propylene oxide (PO) blocks that are arranged in a basic A-B-A structure $\left(\mathrm{EO}_{x}-\right.$ $\mathrm{PO}_{y}-\mathrm{EO}_{x}$ ), are amphiphilic molecules that can be used as structural elements of the polycation-based gene delivery system (polyplexes). ${ }^{4,6}$ The number of hydrophilic EO $(x)$ and hydrophobic PO $(y)$ units can be altered, and the retention of the block copolymer in the organs increases as the length of the hydrophobic PO block increases, or as the hydrophiliclipophilic balance (HLB) value decreases. Kabanov and other researchers ${ }^{12-14}$ reported that Pluronic could enhance cell interactions, DNA transport, and transgene expression, and that Pluronics possess the unique ability to incorporate themselves into cell membranes in the presence of the hydrophobic poly(propylene oxide) chain. In contrast, the hydrophilic EO chain does not interact with lipid membranes but it could be used to prevent the binding of other polymers with the membranes. ${ }^{4}$ The system is stabilized in dispersion by the EO corona in a manner similar to regular Pluronic micelles. To design an effective gene delivery vector, many efforts have been made to improve the transfection efficiency and to reduce the cytotoxicity. Optimal efficacy has been observed with Pluronic copolymers, which have intermediate lengths of PO chains and relatively short EO segments. ${ }^{15}$ The micelles of these copolymers are sufficiently potent in the ability of binding cellular membranes and a relatively high concentration of micelles could be reached in solution. ${ }^{16}$

Based on previous studies, the authors prepared a series of cationic copolymers by grafting low-molecular-weight PEI with Pluronics consisting of different ratios of EO and PO. These copolymers were then evaluated as delivery systems for the plasmid DNA in vitro. The authors further investigated the structure-cellular uptake relationship of low-molecular-weight PEI modified by Pluronic with different $\mathrm{EO} / \mathrm{PO}$ ratios and an HLB that could reduce the cytotoxicity of PEI and accelerate endocytosis of the polyplexes. This study was conducted to formulate a nonviral system for gene delivery and to clarify the relationship between the structure and the function of intracellular trafficking.

\section{Materials and methods \\ Materials}

Branched PEI (molecular weight, 2000) was obtained from Sigma-Aldrich (St Louis, MO). The BASF Corporation (Mount Olive, NJ) kindly provided the Pluronics (F68, P123, P105, L61). Bis-(trichloromethyl) carbonate, N-hydroxysuccinimide, triethylamine, acryloyl chloride, anhydrous dichloromethane, and dithiothreitol (DTT) were purchased from Sinopharm Chemical Reagent Co, Ltd (Shanghai, China) and were used without further purification. A luciferase assay system for physicochemical characterization study and in vitro transfection assay and pGL-3 control vector with SC-40 promoter and enhancer encoding firefly (Photinus pyralis) luciferase were obtained from Promega (Madison, WI). The Institute of Life Science and Technology of Tongji University in Shanghai, China, kindly provided the quantum dots (QDs).

\section{Synthesis of activated Pluronic}

The Pluronic (P123, P105, F68, L61, 0.6 mmol) was dried by co-evaporation with anhydrous toluene under vacuum at $50^{\circ} \mathrm{C}$, dissolved in a toluene/dichloromethane mixture $(3: 1$, $40 \mathrm{~mL}$ ), and treated with bis-(trichloromethyl)-carbonate (1.2 mmol) overnight. The solution was evaporated to dryness under vacuum. The residue was redissolved in a toluene/ dichloromethane mixture $(2: 1,30 \mathrm{~mL})$ and was treated with solid N-hydroxysuccinimide $(2.0 \mathrm{mmol})$ followed by anhydrous triethylamine $(0.28 \mathrm{~mL}, 2.0 \mathrm{mmol})$. After 4 hours of stirring, the solution was filtered and evaporated to dryness. The product was purified on a silica gel column using stepwise elution with trichloromethane methanol (10\%-15\% v/v) mixtures; the yield was about $80 \%-85 \%$.

\section{Synthesis of polymer particle copolymers}

The PEI $(0.10 \mathrm{mmol})$ was dissolved in $10 \mathrm{~mL}$ of anhydrous dichloromethane as solution $\mathrm{A}$, and the predetermined amount of activated Pluronic $(0.01 \mathrm{mmol})$ was dissolved in $10 \mathrm{~mL}$ of anhydrous ethanol as solution B. Solutions A and B were then slowly added to a base solution of anhydrous 
dichloromethane $(10 \mathrm{~mL})$ with constant stirring. The reaction mixture was left overnight at room temperature. After completion of reaction, the conjugate was dialyzed against distilled water at $4{ }^{\circ} \mathrm{C}$ for 2 days using a Spectra/Por ${ }^{\circledR}$ membrane (Carl Roth GmbH \& Co. KG Karlsruhe, Germany) (molecular weight cut-off, 7000) and was lyophilized.

\section{Characterizations of polymer particles (nuclear magnetic resonance/gel permeation chromatography)}

The ratio of Pluronic and PEI in the copolymer samples was determined from proton nuclear magnetic resonance $\left({ }^{1} \mathrm{H}-\right.$ NMR) spectra (Varian, Palo Alto, CA $300 \mathrm{MHz}$ ) using integral values obtained for the $-\mathrm{CH}_{2} \mathrm{CH}_{2} \mathrm{O}$ - protons of Pluronic and the $-\mathrm{CH}_{2} \mathrm{NH}-$ protons of PEI. The ${ }^{1} \mathrm{H}-\mathrm{NMR}$ analysis was carried out with a $10 \mathrm{mg}$ sample of polymer particles (PPs) dissolved in $0.6 \mathrm{~mL}$ of deuterium oxide at room temperature.

Molecular weight and molecular weight distribution of the polymers were determined by gel permeation chromatography with multi-angle laser light scattering (Shimadzu LC-20 AD; Shimadzu, Kyoto, Japan) (laser wavelength, $690 \mathrm{~nm}$ ), using a TSK-GEL G5000PW $\mathrm{XL}_{\mathrm{XL}}$ column (Tosoh, Japan) (temperature, $40^{\circ} \mathrm{C}$ ) operated at a flow rate of $0.4 \mathrm{~mL} / \mathrm{minute}$. Ammonium acetate $(0.2 \mathrm{~mol} / \mathrm{L})$ was used as a mobile phase.

\section{Degradation of PPs}

Degradation of the branched PPs was estimated through the measurement of molecular weight. Briefly, $0.5 \mathrm{~g}$ of each polymer was dissolved in $10 \mathrm{~mL}$ of phosphate-buffered saline (PBS) (Gibco, Invitrogen, Carlsbad, CA) $(0.1 \mathrm{~mol} / \mathrm{L}, \mathrm{pH}$ 7.4) and then incubated at $37^{\circ} \mathrm{C}$ with shaking at $100 \mathrm{rpm}$ for specific time points. After incubation, solutions of polymers were lyophilized and the molecular weight of the lyophilized samples was measured by gel permeation chromatography with multi-angle laser light scattering (laser wavelength, $690 \mathrm{~nm}$ ).

\section{Preparation of PP/DNA complexes}

The charge ratio of the PP/DNA complexes was expressed as the ratio of PP weight to DNA weight (w/w). Complexes were induced to self-assemble by mixing plasmid DNA with appropriate polymer solution (PBS $0.1 \mathrm{~mol} / \mathrm{L}, \mathrm{pH} 7.4$ ) at the desired charge ratio. The complexes were allowed to stand at room temperature for 30 minutes.

\section{Agarose gel retardation assay}

Various amounts of Pluronic-g-PEI dissolved in deionized water were added into the aqueous solution with a fixed amount of plasmid DNA (50 ng/well) and incubated for 30 minutes at room temperature. The mixture was electrophoresed on a $0.7 \%$ (weight/volume) agarose gel for about 30 minutes at $100 \mathrm{~V}$ in the Tris-acetate-ethylenediaminetetraacetic acid buffer (Gibco, Invitrogen, Carlsbad, CA). The gel was stained with ethidium bromide $(0.5 \mathrm{~g} / \mathrm{mL})$ and was illuminated on an ultraviolet illuminator (302 $\mathrm{nm})$ to show the location of the DNA and various levels of polyplex formation.

\section{Measurement of particle size and zeta potential}

The size and zeta potential of cationic polymer/DNA complexes in PBS buffer at room temperature were measured using an electrophoretic light-scattering spectrophotometer (Zetasizer Nano ZS90, Malvern Instruments, Worcestershire, United Kingdom), with scattering angles of $90^{\circ}$. The polyplexes were prepared by adding an appropriate amount of cationic polymer solution based upon desired $\mathrm{w} / \mathrm{w}$ ratios to DNA $(20 \mu \mathrm{g})$ in $250 \mu \mathrm{L}$ of PBS while vortexing. The complexes were incubated at room temperature for 30 minutes before measurement of size and zeta potential was carried out, and all the experiments were performed in triplicate.

\section{DNA protection and release assay}

Each complex solution with PPs to DNA at a weight ratio of 20:1 was divided into equal triplicates. One served as the control and the other two were incubated with DNase I at $37^{\circ} \mathrm{C}$ for 2 hours at a final DNase I concentration of $50 \mathrm{U} / \mathrm{g}$ of plasmid DNA. Ethylenediaminetetraacetic acid $(3 \mu \mathrm{L}, 0.5 \mathrm{~mol} / \mathrm{L})$ was added to one of these two solutions to immediately stop DNA degradation, and then $3 \mu \mathrm{L}$ of sodium dodecyl sulfate $(10 \%$, w/v) was added to displace DNA. Naked DNA, with and without DNase I treatment, served as the control. All samples were then placed in an ice bath. Finally, 0.7\% agarose gel electrophoresis was performed to evaluate the integrity of DNA in the complexes.

Then $10 \mu \mathrm{L}$ of PBS (as control) or of PBS containing DTT was added to give a final concentration of DTT $10 \mathrm{mmol} / \mathrm{L}$ in the resultant solution, and the dispersions were incubated for 60 minutes. The samples were then analyzed by gel electrophoresis, as described.

\section{Cytotoxicity assay}

Cell toxicity of PP/DNA complexes was investigated by cell proliferation assay. HeLa cells were seeded in 96-well plates at an initial density of $1 \times 10^{4}$ cells/well and were incubated for 18-20 hours to reach $80 \%$ confluency at treatment. The culture medium was then replaced with fresh serum-free media 
containing serial dilutions of PP/DNA or PEI complexes at various concentrations $(4,6,8,16,24$, and $32 \mathrm{mg} / \mathrm{mL})$. After 24 hours of incubation, $20 \mu \mathrm{L}$ of CellTiter $96^{\circledR} \mathrm{AQ}_{\text {ueous }}$ One Solution Reagent (Promega) was added to each well and the cells were further incubated for 1-4 hours. The absorbance was then measured at $490 \mathrm{~nm}$ using an enzyme-linked immunosorbent assay plate reader (Model 318MC, Sanco, Shanghai, China) to obtain the metabolic activity of the cells. The spectrophotometer was calibrated to 0 absorbance using culture medium without cells. The cell viability was calculated according to the following equation:

$$
\begin{aligned}
\text { Cell viability }(\%)= & \left(\mathrm{A}_{\text {test }} / \mathrm{A}_{\text {control }}\right) \times 100(\text { mean } \pm \text { standard } \\
& \text { deviation, } \mathrm{n}=6),
\end{aligned}
$$

where $\mathrm{A}_{\text {test }}$ is the absorbance of the PPs or PEI-treated cells and $\mathrm{A}_{\text {control }}$ is the absorbance of the untreated cells.

\section{Luciferase assay in vitro}

HeLa cells were seeded in a 24-well plate at a density of $1 \times 10^{5}$ cells per well and were incubated for 18-24 hours to $60 \%-70 \%$ confluency. Then $3 \mu \mathrm{g}$ of pGL 3 was formulated with the different polymers at various $\mathrm{w} / \mathrm{w}$ ratios and incubated for 30 minutes at room temperature. Serum-free Dulbecco's modified Eagle's medium (DMEM) (Gibco, Invitrogen, Carlsbad, CA) was added to the complex-dispersed medium. The polymer/DNA complexes dispersed in serum-free DMEM were added to the 24 -well plate and incubated for 5 hours at $37^{\circ} \mathrm{C}$ under a $5 \% \mathrm{CO}_{2}$ atmosphere. The medium was then replaced with growth medium containing serum and was incubated for 48 hours. The luciferase assay was carried out according to the manufacturer's instructions (Promega). The relative light units per second determined in $20 \mu \mathrm{L}$ of cell extract were converted into the amount of luciferase (pg) using a luciferase standard curve. The standard curve was obtained by diluting known amounts of recombinant luciferase (E1701; Promega) in lysis buffer used to extract cells. The amount of cell protein in $50 \mu \mathrm{L}$ of cell extract was determined using a Micro-BCA protein assay kit (Pierce, Rockford, IL). The transfection efficiency was expressed as relative light units per milligram of cell protein. All transfection experiments were performed in triplicate.

\section{Cellular uptake study}

Green QDs were used as molecular probes to label F68-, P123-, P105-, and L61-PEI 2KD. Cells were seeded on glass coverslips and were then transfected with the PP/DNA complexes (10:1, w/w), which had been incubated for $1,3,5$, 10,20 , and 30 minutes in serum-free DMEM at $37^{\circ} \mathrm{C}$ before addition into the cell culture. At the end of each time point, cells were washed, fixed (using 4\% paraformaldehyde), and examined under a confocal microscope (FluoView ${ }^{\circledR}$ FV1000; Olympus, Tokyo, Japan).

\section{Statistical analysis}

The data are presented as the mean plus or minus the standard deviation. Statistically significant differences were determined using two-sample Student's $t$-tests and analysis of variance, with $P<0.05$ as the level of statistical significance.

\section{Results and discussion Synthesis and characterization of PP copolymers}

Cationic copolymers were synthesized by grafting polyether chains, Pluronic, to the amino groups of PEI. The authors chose four different types of Pluronic, and the HLB order was $\mathrm{F} 68>\mathrm{P} 105>\mathrm{P} 123>\mathrm{L} 61$ (Table 1$).{ }^{17}$ In all cases, free hydroxyl groups of the Pluronic polyether chains were activated by succinimidyl carbonate in advance and were then linked to the amino groups of PEI, as shown in Figure $1 .^{18}$ The copolymers were separated from unconjugated polymers by dialysis, and then the preparation of PP copolymers was determined from ${ }^{1} \mathrm{H}-\mathrm{NMR}$ spectra using integral values obtained for the $-\mathrm{CH}_{2} \mathrm{CH}_{2} \mathrm{O}-$ protons (Pluronic F68) and the $-\mathrm{CH}_{2} \mathrm{CH}_{2} \mathrm{NH}-$ protons (PEI). Figure 2 shows the ${ }^{1} \mathrm{H}-\mathrm{NMR}$ spectra of Pluronic-g-PEI in deuterium oxide, where $-\mathrm{CH}_{2} \mathrm{CH}_{2} \mathrm{O}-$ proton peaks appear at $\delta 3.8 \mathrm{ppm}$ and $-\mathrm{CH}_{2} \mathrm{CH}_{2} \mathrm{NH}-$ proton peaks appear at $\delta 2.7-3.5 \mathrm{ppm}$.

\section{Analysis and characterization of polyplex formation}

Gel retardation assays were performed to investigate the ability of PPs to condense DNA via electrostatic interactions between the PEI and DNA at various w/w ratios (Figure 3).

Table I Characteristics of Pluronic ${ }^{\circledR}$ block copolymers

\begin{tabular}{llllll}
\hline Copolymer & MW $^{\mathrm{a}}$ & $\begin{array}{l}\text { Average } \\
\text { no EO } \\
\text { units }(x)^{\mathrm{b}}\end{array}$ & $\begin{array}{l}\text { Average } \\
\text { no PO } \\
\text { units }(\mathbf{y})^{\mathrm{b}}\end{array}$ & HLB $^{\mathrm{c}}$ & $\begin{array}{l}\text { CMC } \\
(\mathbf{m o l} / \mathbf{L})^{\mathrm{d}}\end{array}$ \\
\hline F68 & 8400 & 152.73 & 28.97 & 29 & $4.8 \times 10^{-4}$ \\
PI05 & 6500 & 73.86 & 56.03 & 15 & $6.2 \times 10^{-6}$ \\
PI23 & 5750 & 39.2 & 69.4 & 8 & $4.4 \times 10^{-6}$ \\
L6I & 2000 & 4.55 & 31.03 & 3 & $1.1 \times 10^{-4}$ \\
\hline
\end{tabular}

Notes: a The average MWs provided by the manufacturer (BASF Corporation, Mount Olive, $\mathrm{NJ}$ ); b the average numbers of $\mathrm{EO}$ and $\mathrm{PO}$ units were calculated using the average MW; CHLB values and cloud points were determined by the manufacturer; ${ }^{\mathrm{d}} \mathrm{CMC}$ values were determined previously, using pyrene as a probe.

Abbreviations: CMC, critical micelle concentration; EO, ethylene oxide; HLB, hydrophilic-lipophilic balance; MW, molecular weight; PO, propylene oxide. 

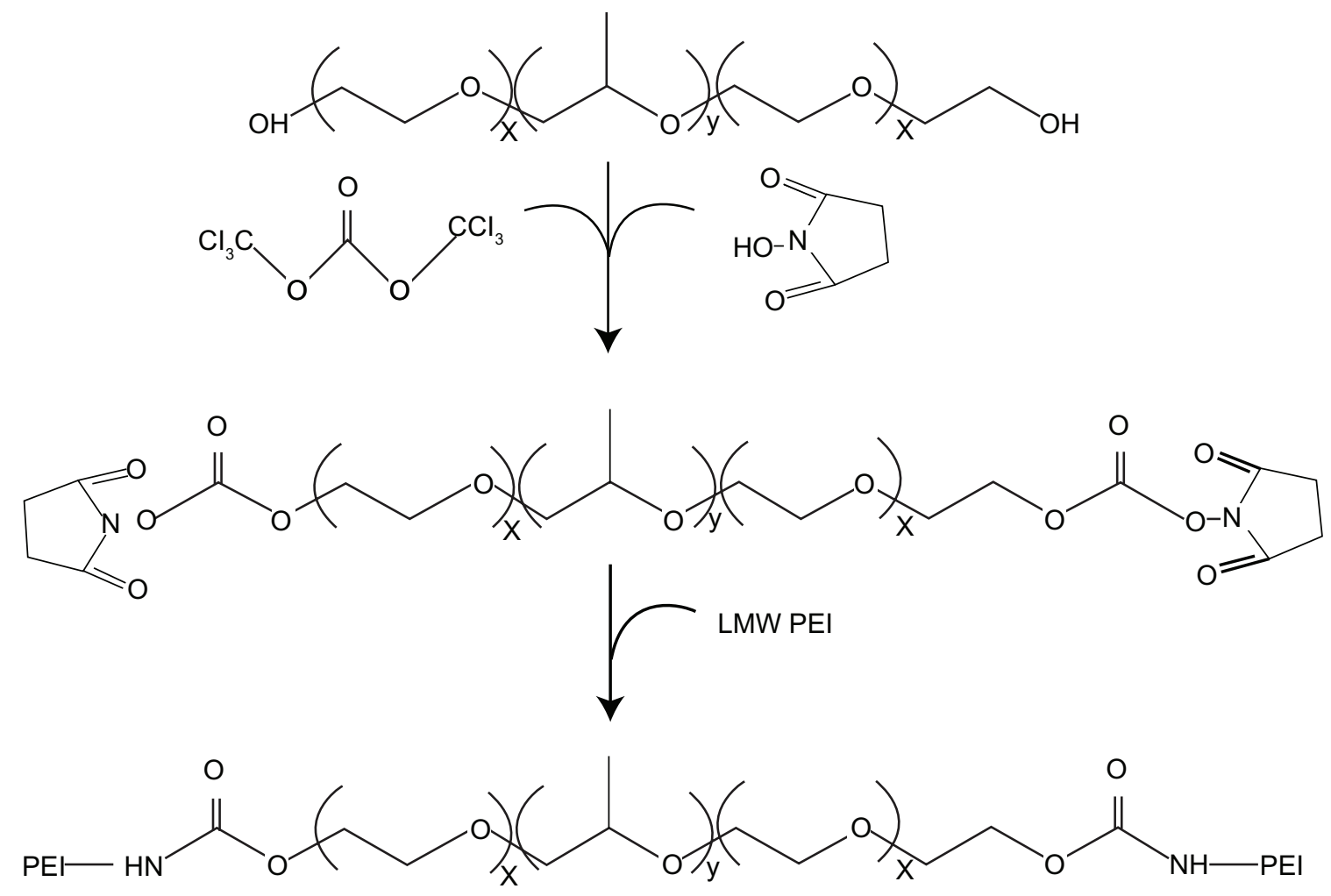

Figure I Synthetic scheme of Pluronic ${ }^{\circledR}$-g-polyethylenimine (Pluronic-g-PEI).

Abbreviation: LMW, low-molecular-weight.

In this experiment, movement of the plasmid DNA in the gel was retarded as the amount of the cationic copolymer increased, demonstrating the copolymer bound to the DNA, neutralizing its charge. ${ }^{4}$ As the $\mathrm{w} / \mathrm{w}$ ratios exceeded the neutralization composition, the complexes migrated slightly toward the anode, suggesting they have a small positive charge. The assay confirmed the polymer/DNA ratio required for complete condensation and retardation of DNA. In addition, for unconjugated PEI, DNA was retarded at a w/w ratio of 0.2 (data not shown). For F68-PEI 2KD, P105-PEI 2KD, P123-PEI 2KD, L61-PEI 2KD, and PEI 2KD, DNA was retarded at a $\mathrm{w} / \mathrm{w}$ ratio of $0.8,0.8,0.4,0.6$, and 0.6 , respectively. Thus, it could shield the positive charge of the complex surface and easily condense the DNA as the amount of Pluronic increased.

Figure 4 shows that in the absence of DTT, PPs could completely retard plasmid DNA migration at the $\mathrm{w} / \mathrm{w}$ ratio of 0.8:1. However, DNA release from PP polyplexes could be observed by gel electrophoresis in the presence of dithiothreitol $5.0 \mathrm{mmol} / \mathrm{L}$, mimicking the intracellular reducing environment containing glutathione $0.1-10 \mathrm{mmol} / \mathrm{L}$. For the nondegradable control polymer PEI $25 \mathrm{KD}$, there was no DNA released from PEI/DNA complexes in the presence of DTT. ${ }^{19}$ The rapid DNA release in the reduction condition suggests that the significant polyplex dissociation was mainly owing to the cleavage of the amide bond with DTT, leading to increased DNA release and increased gene expression. ${ }^{20}$

\section{Degradation study and resistance to nuclease degradation}

Degradation of gene delivery polymers in vivo is important for safe and efficient gene delivery, because the appropriate degradation of the polymer could reduce cytotoxicity and facilitate elimination through the excretion pathway in vivo. ${ }^{21,22}$ Nondegradable PEI may accumulate in vivo because of a lack of degradation or excretion pathways, causing potential cytotoxicity. Therefore, it is expected that ester bonds in these polymers are susceptible to hydrolysis in physiological conditions, forming poloxamer oligomers and low-molecular-weight polyethylene. ${ }^{23}$ Figure 5 shows degradation of the hyperbranched PPs over time at $\mathrm{pH} 7.4$ and $37^{\circ} \mathrm{C}$. The results indicate that the polymers degraded very slowly and the degradation rate of PPs was highly dependent on the hydrophilicity of the polymer.

The primary responsibility of any gene delivery system is to protect DNA from degradation by nucleases. ${ }^{24}$ Naked DNA was digested when treated with DNase I (Figure 6, Lane 1). The other two complexes could encapsulate DNA completely and 


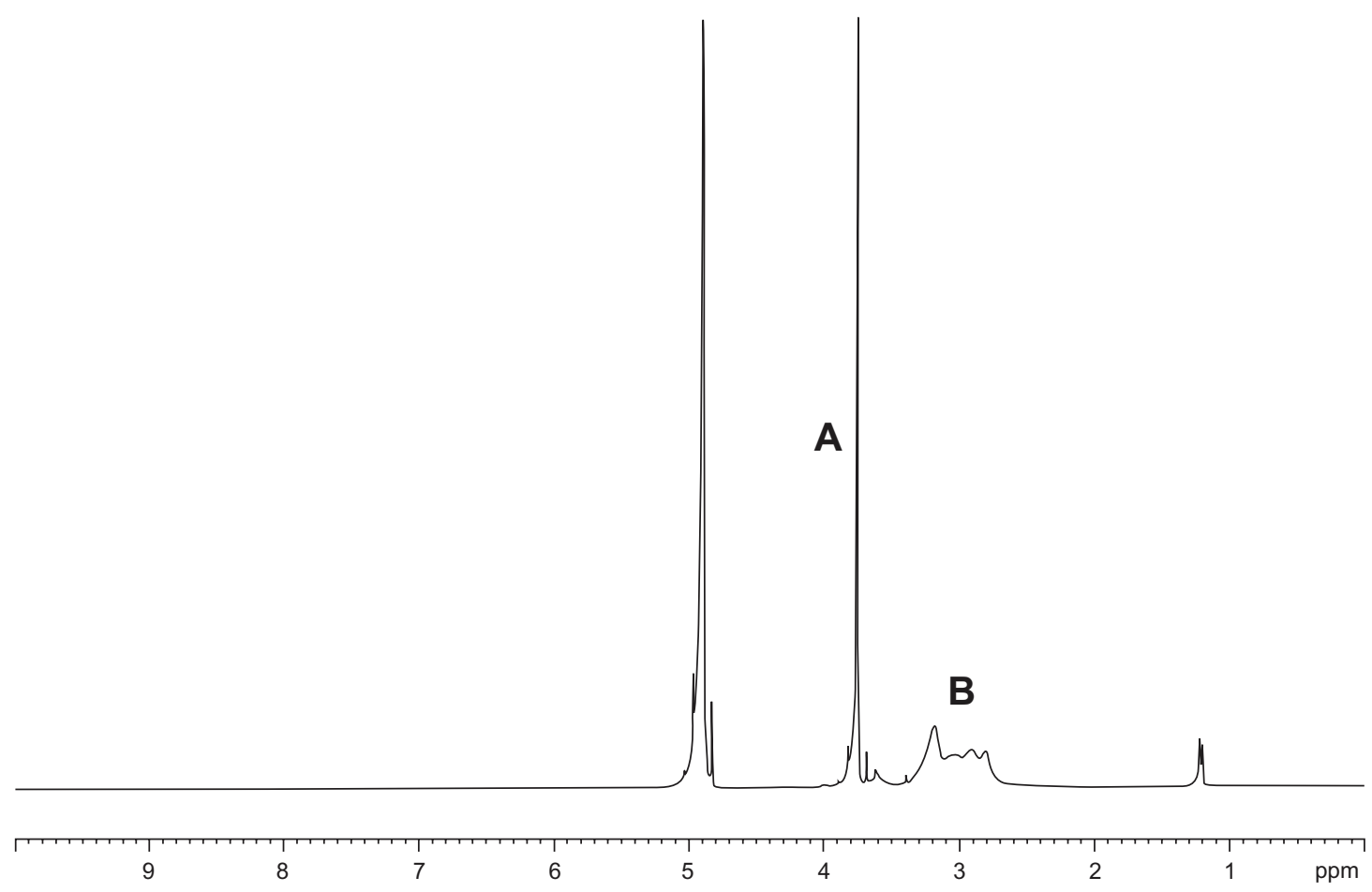

Figure 2 Representative proton nuclear magnetic resonance spectra $(300 \mathrm{MHz})$ of the $-\mathrm{CH}_{2} \mathrm{CH}_{2} \mathrm{O}-$ proton in Pluronic ${ }^{\circledast} \mathrm{F} 68$ at about $\delta 3.8 \mathrm{ppm}(\mathbf{A})$ and the $-\mathrm{CH}_{2} \mathrm{CH}_{2} \mathrm{NH}_{-}$ repeating unit of polyethylenimine in $\mathrm{F} 68$-polyethylenimine $2 \mathrm{KD}$ at $\delta 2.7-3.5 \mathrm{ppm}(\mathbf{B})$ in deuterium oxide.
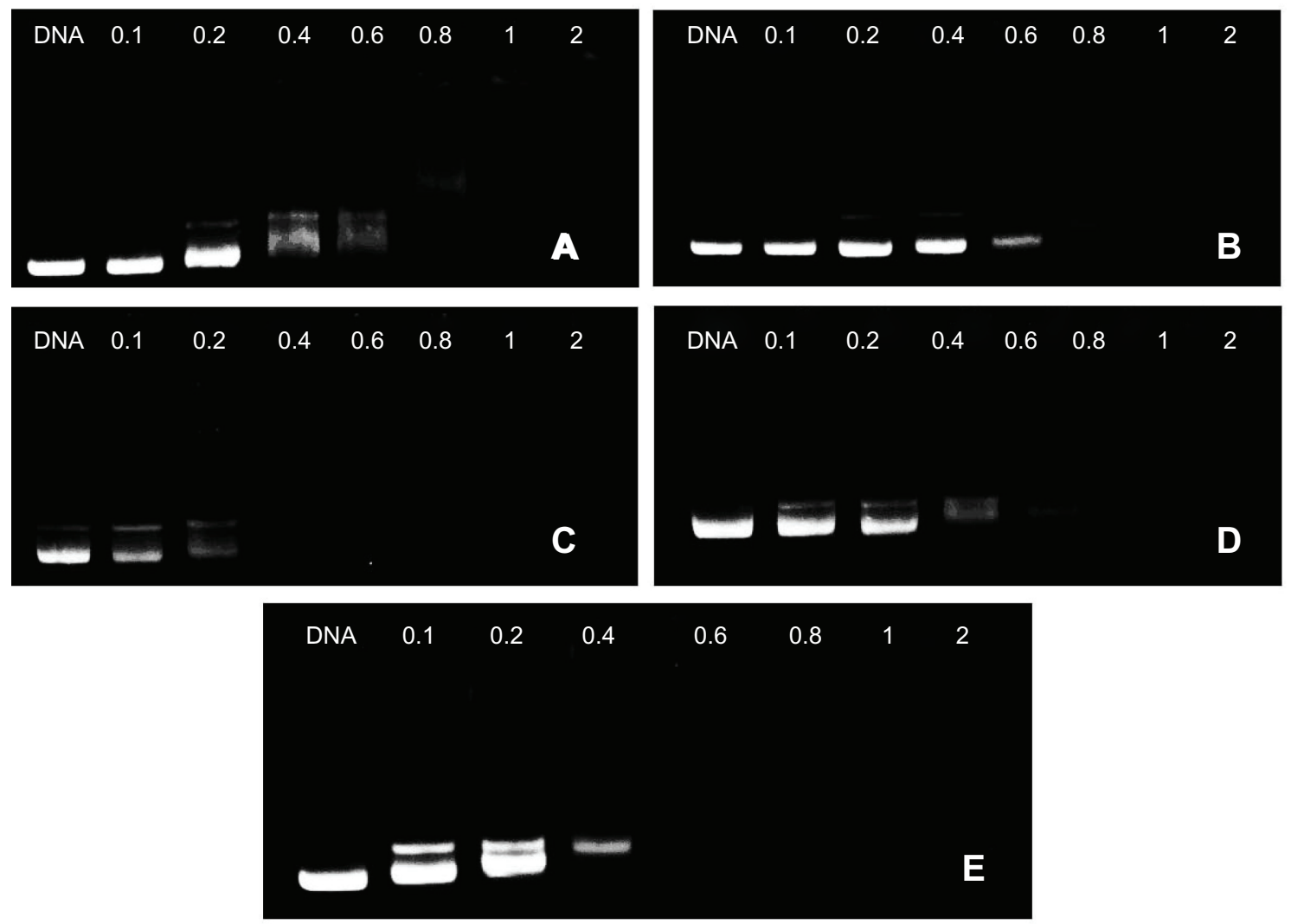

Figure 3 Agarose gel electrophoresis of complexes at various weight-to-weight (polymer particle/DNA) ratios: (A) F68-polyethylenimine (F68-PEI) 2KD, (B) PI05-PEI 2KD, (C) PI23-PEI 2KD, (D) L6I-PEI 2KD, and (E) PEI 2KD.

Note: The used plasmid DNA was $0.1 \mu g$, and copolymer/DNA complexes were prepared in phosphate-buffered saline. 


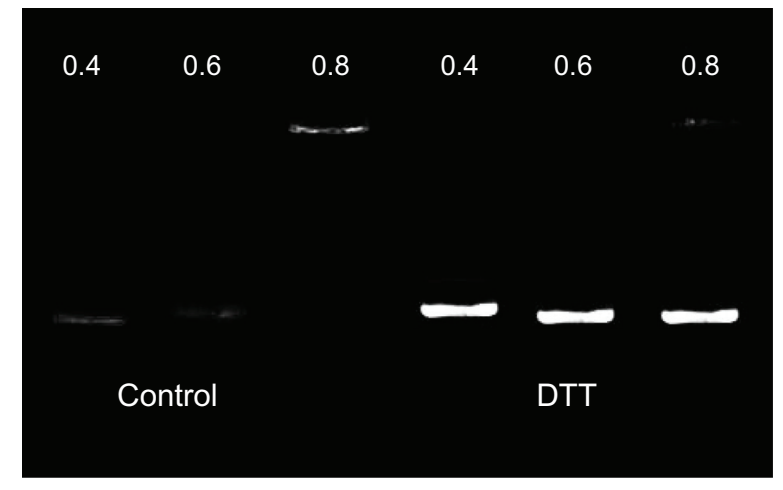

Figure 4 The influence of dithiothreitol (DTT) on PI05-polyethylenimine 2KD/DNA complexes: other than the later three being treated with DDT $10 \mathrm{mmol} / \mathrm{L}$, the two groups of PI05-polyethylenimine 2KD/DNA complexes were identical.

protect it from digestion by DNase I (Figure 6, Lane 3). Plasmid DNA that recovered from the complexes remained nearly intact after further treatment with sodium dodecyl sulfate (an intensely electronegative substance that can displace DNA in the complexes) after DNase I digestion (Figure 6, Lane 2).

\section{Particle size and zeta potential measurement}

To investigate the effect of the cationic copolymer structure on the size of the complexes, each cationic copolymer was allowed to form complexes at different w/w ratios. Figure 7 shows that the mean particle size decreased significantly as the $\mathrm{w} / \mathrm{w}$ ratio of PP/DNA increased, most probably because their high surface charge could condense DNA more effectively. The size of the particles formed in these systems

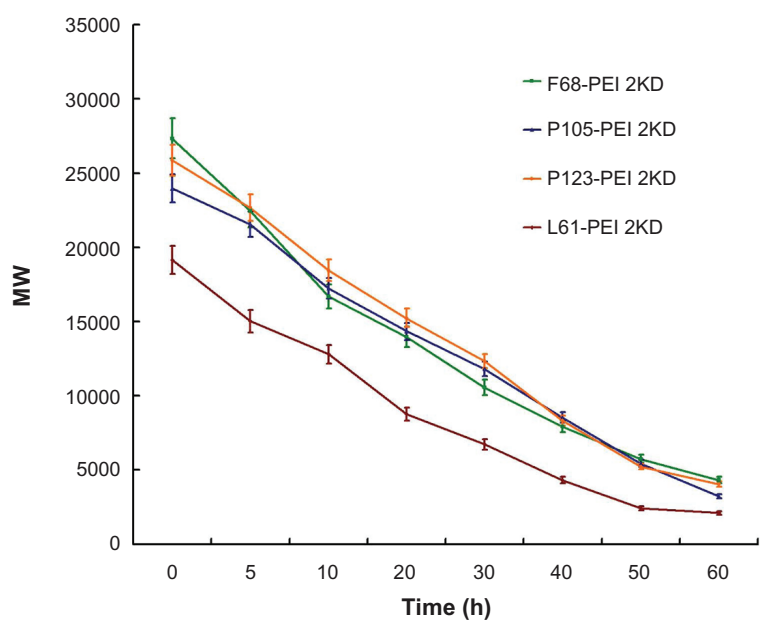

Figure 5 Degradation of polymer particles - copolymers were dissolved in phosphate-buffered saline $(0.1 \mathrm{~mol} / \mathrm{L}, \mathrm{pH} 7.4)$, and were incubated at $37^{\circ} \mathrm{C}$ with shaking at $100 \mathrm{rpm}$.

Notes: The same experiment was repeated three times for statistical analysis. Determination of molecular weight was measured by gel permeation chromatography with multi-angle laser light scattering $(n=3)$.

Abbreviation: PEl, polyethylenimine.

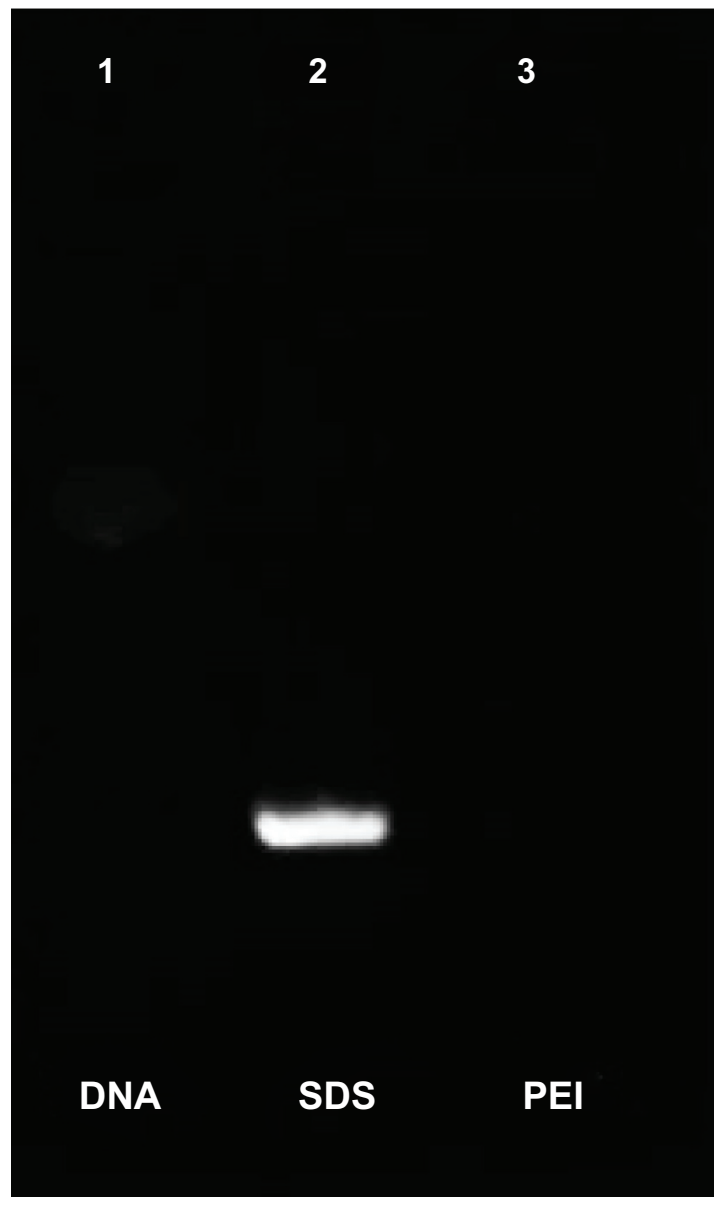

Figure 6 The ability of anti-DNase of PI23-polyethylenimine (PI23-PEI) could protect the DNA out of DNase. Lane I: naked plasmid DNA treated with DNase; Lane 2: polymer particle/DNA complexes treated with DNase and then with sodium dodecyl sulfate (SDS); Lane 3: polymer particle/DNA complexes as control.

varies from 80 to $220 \mathrm{~nm}$ depending on the composition of the complex, which is beneficial to efficient endocytosis and gene transfer. ${ }^{25}$

No precipitation was observed at any $\mathrm{w} / \mathrm{w}$ ratio in the range of concentrations studied. Compared with unmodified PEI/DNA complexes, addition of Pluronic to PEI-based polyplexes had little effect on polyplex particle size but it led to a good stability of polyplexes. ${ }^{10}$

A positive surface charge of untargeted polyplexes is necessary for binding to anionic cell surfaces, which consequently facilitates cell uptake. ${ }^{26}$ However, strong cationic charges of the complexes are often cytotoxic. ${ }^{24}$ Changes in the charge of the complexes upon addition of the cationic copolymers were further characterized by measuring the zeta potential of various w/w ratios. Figure 8 shows zeta potentials of the complexes according to the w/w ratio. The zeta potential of Pluronic- $g$-PEI was significantly lower than that observed for unmodified PEI at various w/w ratios. As the $\mathrm{w} / \mathrm{w}$ ratio increased, so the zeta potential of the complexes 


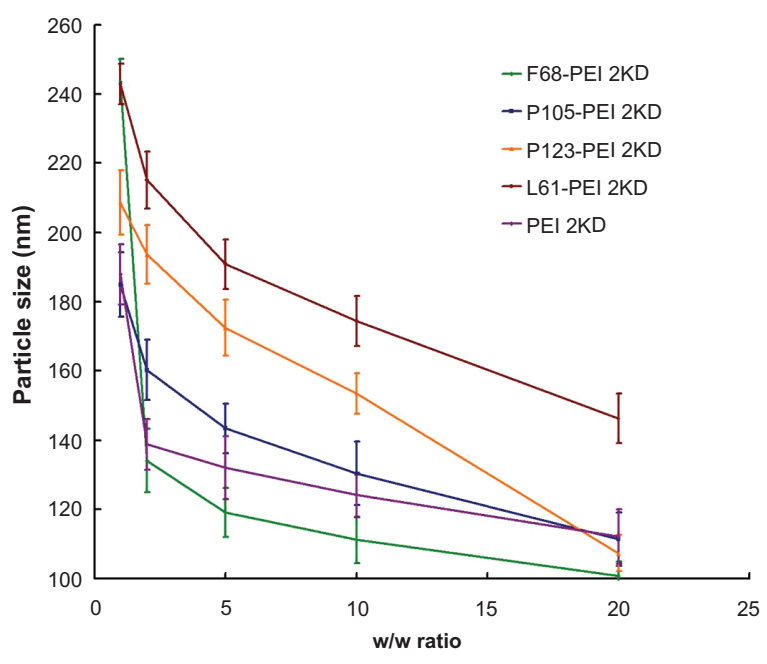

Figure 7 Particle sizes of polymer particle/DNA complexes, with polyethylenimine (PEI)/DNA as control.

Notes: The same experiment was repeated three times for statistical analysis. Data expressed as mean values (plus or minus standard deviation, $n=3$ ).

also increased. Thus, the zeta potential measurements were consistent with the results of the agarose gel electrophoresis experiments.

\section{Cytotoxicity assay}

Knowing that the high-molecular-weight PEI is limited by its relatively high cytotoxicity when it is used as a transfection reagent, the authors focused on reducing the cytotoxicity and increasing the transfection efficiency. The cell proliferation assay was used to compare the cytotoxicity of Pluronic- $g$-PEI and PEI 25KD polymer. Figure 9 shows the cytotoxicity of the polymers at various concentrations with HeLa cell lines. It was found that Pluronic- $g$-PEI had significantly higher cell

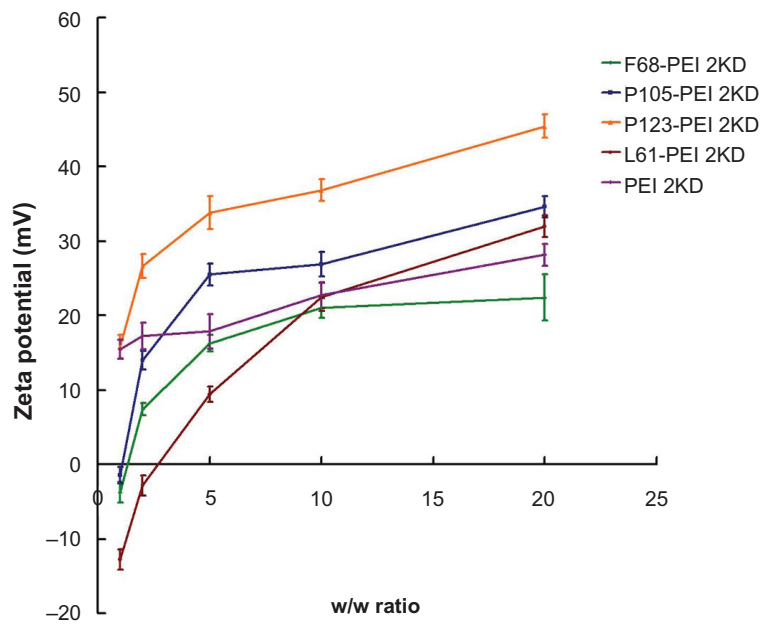

Figure 8 Zeta potential of polymer particle/DNA complexes, with polyethylenimine (PEI)/DNA as control.

Notes: The same experiment was repeated three times for statistical analysis. Data expressed as mean values (plus or minus standard deviation, $n=3$ ). viability than PEI 25KD at any concentration $(P<0.01)$. It is worth noting that the modified Pluronic- $g$-PEI showed significantly higher cell viability at various concentrations, especially the high concentration, suggesting that transfection efficiency could be improved by administration of more PPs if necessary, knowing that the cytotoxicity is low.

The enhanced cell viability is undoubtedly the result of the formation of low-toxic building blocks. ${ }^{21}$ The cytotoxicity of cationic polymers is thought to be a result of the multiple attachment of PEI to the cell surface and the membrane-damaging effects. ${ }^{27}$ The results of this study show that PEI macromolecules can be conjugated with Pluronic and that PPs are degradable under physiological conditions. The degradation products of the polymer are low-molecular-weight PEI and Pluronics, which are practically nontoxic and are rapidly excluded out of the cell nucleus and the cytoplasm or eliminated from the body. Thus, the safety of Pluronic formulations may be an important advantage for their utilization in nonviral gene delivery. Meanwhile, the number of PEI attachments to cell surfaces may also be reduced, resulting in a lower cytotoxicity to cells.

\section{In vitro transfection efficiency}

Complexes formed between plasmid DNA and cationic copolymers were assessed for their in vitro transfection activity utilizing a transient expression of luciferase reporter in HeLa cell lines. For all cationic polymers, the efficacy of transfection was dependent on the electrostatic interactions and the "proton sponge effect" of PEI. ${ }^{3}$ As shown in Figure 10, transfection efficiency of PPs rapidly increased with the increase in ratio of PEI $2 \mathrm{KD} /$ Pluronic, which can be explained by the high degree of modification of PEI 2KD leading to an increase in positive surface and structural compactness of the complexes. The highest luciferase expression level was obtained at P105-PEI 2KD, and the Pluronic- $g$-PEI showed higher gene transfer ability than PEI 2KD. The enhanced transfection efficiency of Pluronic-g-PEI over PEI 2KD is because of the introduction of the hydrophilic EO chain and the hydrophobic PO chain of Pluronics. The hydrophilic EO chains extend into water and sterically prevent the complexes from approaching each other, ${ }^{28}$ and they can shield the positive surface charge of complexes. ${ }^{27}$ Therefore, the EO chain can reduce toxicity and improve the colloidal stability of the polymer/DNA complexes as well. ${ }^{26}$ Also, the PO chain is believed to enhance lipophilic complexes, which possibly possess the ability of interacting with biological membranes and enhancing transport of the complexes into cells. ${ }^{4}$ Therefore, the results of this study show that reducing cytotoxicity and increasing hydrophobicity and stability enhanced 


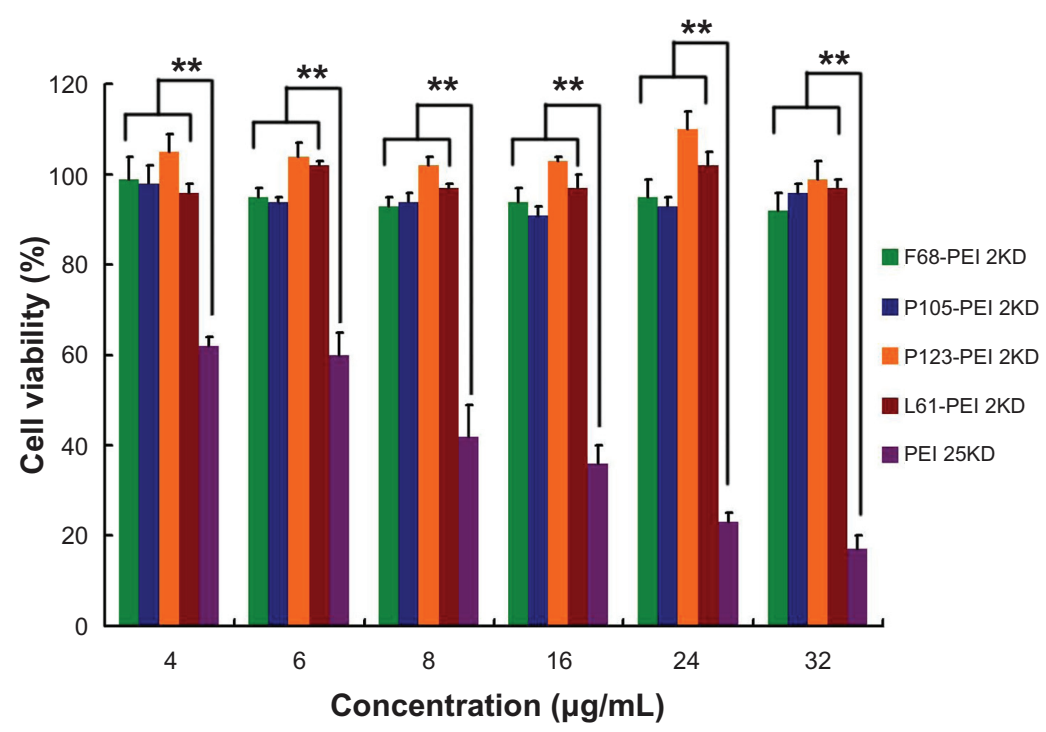

Figure 9 Cytotoxicity of polymer particles at various concentrations in HeLa cell lines by Cell Counting Kit-8 assay (CCK-8, Dojindo, Japan).

Notes: The same experiment was repeated six times for statistical analysis. Each data point represents the mean plus or minus the standard deviation $(\mathrm{n}=6$, $* * P<0.0 \mathrm{I})$.

Abbreviation: PEl, polyethylenimine.

the efficacy of the newly synthesized Pluronic-g-PEI in transfection compared with unmodified PEI.

\section{Cellular uptake study}

Efficient entry of synthetic polymers inside cells is a central issue in polymeric drug delivery. ${ }^{16}$ There is ample evidence that polycationic compounds can interact with negatively charged cellular membranes. However, amphiphilic block copolymers, such as Pluronic, depend on their aggregation state to cellular membranes and are usually taken into cells by endocytosis. ${ }^{14}$ Previous research has suggested that the addition of Pluronic could intensify nonspecific endocytosis in several cells and could dramatically increase cellular uptake, nuclear transport, and transfection efficacy of polyplexes. ${ }^{12}$ Furthermore, the effect of Pluronic on cell uptake was usually observed as early as 60 minutes after exposure. ${ }^{10}$ The magnitude of the effect varied for each Pluronic type, mainly depending on the HLB value. A high HLB value for Pluronic could significantly improve serum stability of the complex. However, complexes with a lower HLB value should theoretically show marked improvement in cellular uptake compared with those with a higher HLB value.

The authors used confocal microscopy to study the intracellular trafficking of representative QDs labeled PPs. Figure 11 shows the cellular trafficking of PPs at the specific time. F68-PEI 2KD presented a slower association with

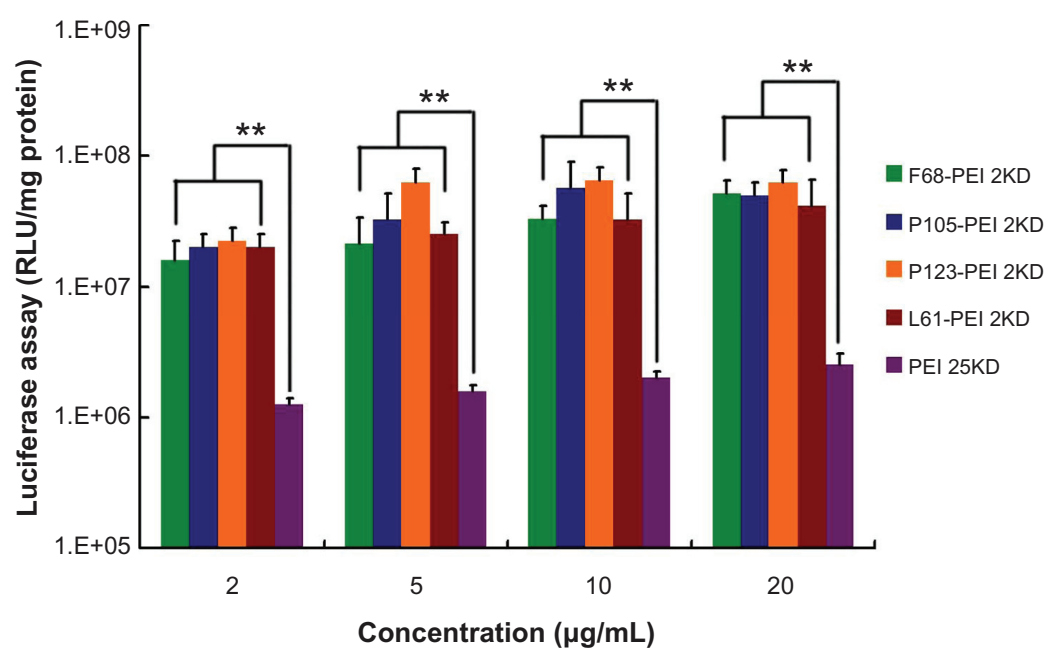

Figure 10 Transfection efficiency of different polymer particle/DNA complexes at the HeLa cell line.

Notes: The same experiment was repeated six times for statistical analysis. Each data point represents the mean plus or minus the standard deviation $(\mathrm{n}=6$, $* * P<0.0 \mathrm{I})$. Abbreviations: PEl, polyethylenimine; RLU, relative light unit. 
outer membranes of HeLa cells (about 5-10 minutes) and homogeneous distribution in the cytoplasm (Figure 11A). This is possibly because the reduction of serum-mediated aggregation of gene transfer was prevented by the addition of high-HLB-value Pluronic F68. Serum stability of nonviral vectors is known to be a crucial factor for successful in vivo gene delivery, and therefore the authors think that these nonviral vectors incorporated with a higher HLB value for Pluronic could be used as potential vehicles for in vivo delivery of DNA because of marked improvement of their serum stability.
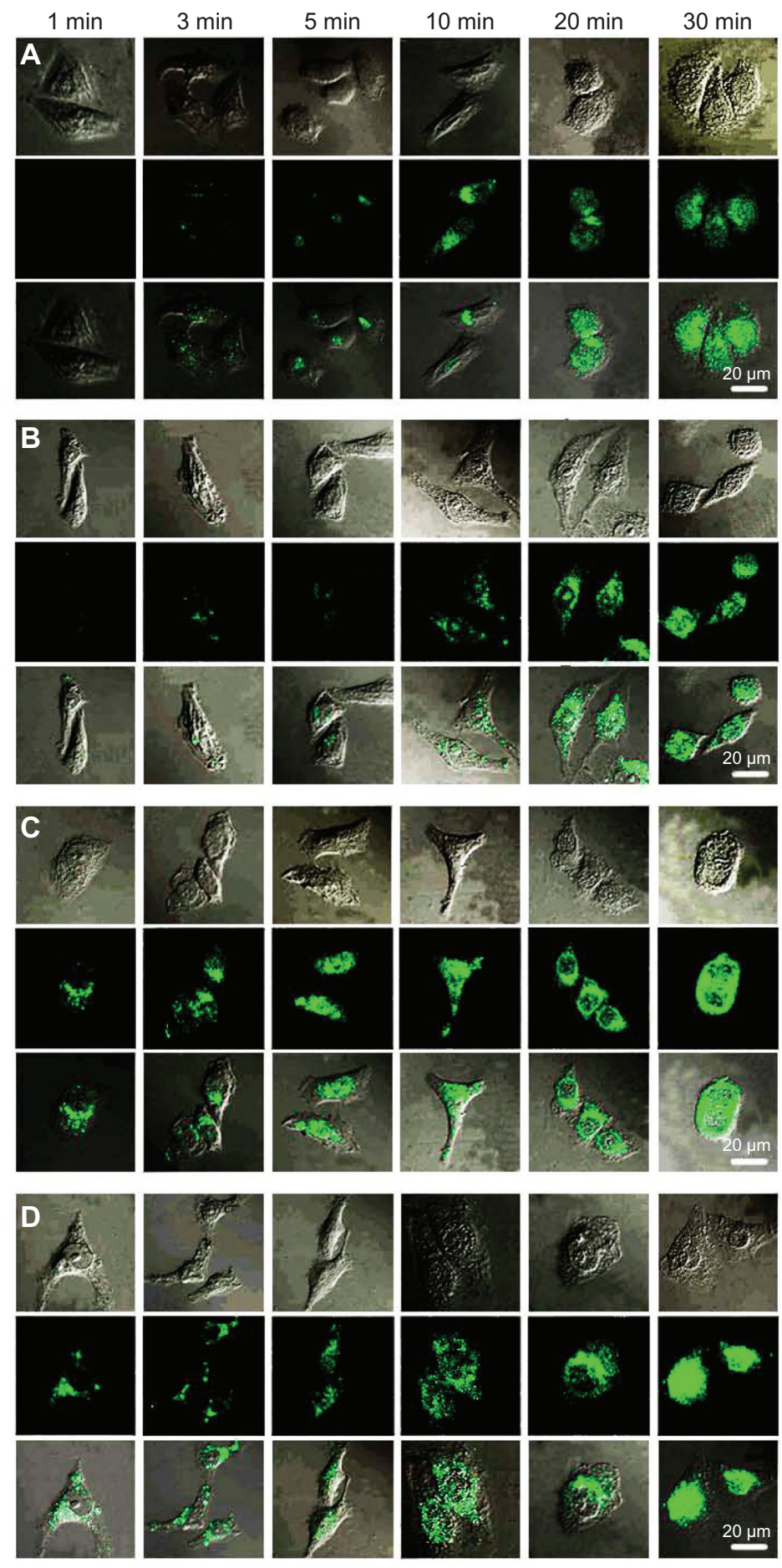

Figure II Cellular trafficking of (A) F68-polyethylenimine (F68-PEI) 2K, (B) PI05-PEI 2K, (C) PI23-PEI 2K, and (D) L6I-PEI 2K analyzed by confocal microscopy in HeLa cells.

Notes: The first line of each group shows the respective transmitted light image, the second line shows the fluorescence micrographs of the same field, and the images in the third line are the merged pictures. Micrographs obtained at magnification $400 \times$. 
Similar pictures were obtained for P123-PEI 2KD and P105-PEI 2KD. After 30 minutes of incubation, the two PPs were mainly associated with the outer membrane, and significant quantities of drugs were already observed in cytosol (Figure 11B and C). This result reveals that P123/ P105-PEI 2KD complexes preferred intracellular accumulation sites in the perinuclear region after 30 minutes of incubation. The adjunction of Pluronic P123/P105, which had intermediate lengths of PO chains, relatively short EO segments, and appropriate HLB value, could not only form a stable dispersion but also facilitate cellular uptake of the synthetic polymers. ${ }^{29}$ Therefore, P123/P105-PEI $2 \mathrm{KD}$ could be considered as a potential nonviral vector of systemic gene delivery, with a wide application in DNA transfection.

L61-PEI 2KD showed a rapid association with outer membranes of HeLa cells (1 minute of incubation) (Figure 11D) because of the larger component of hydrophobic PO chain. After 30 minutes of incubation, transfection with L61-PEI $2 \mathrm{KD}$-based polyplexes resulted in a more localized appearance in the nucleus and a less diffuse appearance throughout the cytoplasm than with the other Pluronics. Although Pluronic with the lowest HLB value could not show much improvement in transfection activity under serum-containing or serum-free conditions, it could lead to a substantial increase in drug accumulation and a change in cellular distribution. ${ }^{30}$ These polyplexes could be used as the vector of genes that are essential to express at the nucleus of cells.

All evidence indicates that the supramolecular architecture of Pluronics may play a role in facilitating the entry of polyplexes through cell membranes and in regulating cellular distribution of the polyplexes.

\section{Conclusion}

This work reports the significant evaluation of the design and formulation of a DNA-polycation polyplex based on a Pluronic-PEI conjugate and the characterization of the cationic graft copolymer system, with the goal of developing a better understanding of this multicomponent delivery system. Complete understanding of this system is particularly important in light of the fact that Pluronics can exhibit biological activity, including effects on enhancing DNA cellular uptake, nuclear translocation, and gene expression. The authors' work indicates that the addition of Pluronics can significantly facilitate intracellular trafficking and can change cellular distribution. The Pluronics with a higher HLB value lead to homogeneous distribution in the cytoplasm; those with a lower HLB value prefer to localize in the nucleus.
As is well known, plasmid DNA should enter the nucleus before effective gene expression, whereas small interfering RNA and microRNA always play their regulatory roles in cytosol. Therefore, it is expected that these molecules are worth exploring as components in the cationic copolymers as the DNA or small interfering RNA/microRNA delivery system, respectively, in the near future.

\section{Acknowledgments}

The authors acknowledge the financial support of National Natural Science Foundation, China (30873178, 30973459, 81072100,81172514 , and 81101658 ). The authors thank Dr WangYue from the Department of Medical Genetics, Second Military Medical University, Shanghai, for his valuable suggestions and helpful discussions.

\section{Disclosure}

The authors report no conflicts of interest in this work.

\section{References}

1. De Smedt SC, Demeester J, Hennink WE. Cationic polymer based gene delivery systems. Pharm Res. 2000;17(2):113-126.

2. Wu X, Ding B, Gao J, et al. Second-generation aptamer-conjugated PSMA-targeted delivery system for prostate cancer therapy. Int $J$ Nanomedicine. 2011;6:1747-1756.

3. Cho KC, Choi SH, Park TG. Low molecular weight PEI conjugated pluronic copolymer: useful additive for enhancing gene transfection efficiency. Macromol Res. 2006;14(3):348-353.

4. Lee K, Bae KH, Lee Y, Lee SH, Ahn CH, Park TG. Pluronic/ polyethylenimine shell crosslinked nanocapsules with embedded magnetite nanocrystals for magnetically triggered delivery of siRNA. Macromol Biosci. 2010;10(3):239-245.

5. Gebhart CL, Kabanov AV. Evaluation of polyplexes as gene transfer agents. J Control Release. 2001;73(2-3):401-416.

6. Nguyen HK, Lemieux P, Vinogradov SV, et al. Evaluation of polyetherpolyethyleneimine graft copolymers as gene transfer agents. Gene Ther. 2000;7(2):126-138.

7. Lungwitz U, Breunig M, Blunk T, Göpferich A. Polyethyleniminebased non-viral gene delivery systems. Eur J Pharm Biopharm. 2005; 60(2):247-266.

8. Liu T, Yu X, Kan B, et al. Enhanced gene delivery using biodegradable poly(ester amine)s (PEAs) based on low-molecular-weight polyethylenimine and poly(epsilon-caprolactone)-pluronic-poly(epsiloncaprolactone). J Biomed Nanotechnol. 2010;6(4):351-359.

9. Neu M, Fischer D, Kissel T. Recent advances in rational gene transfer vector design based on poly(ethylene imine) and its derivatives. J Gene Med. 2005;7(8):992-1009.

10. Yang Z, Sahay G, Sriadibhatla S, Kabanov AV. Amphiphilic block copolymers enhance cellular uptake and nuclear entry of polyplexdelivered DNA. Bioconjug Chem. 2008;19(10):1987-1994.

11. Mintzer MA, Simanek EE. Nonviral vectors for gene delivery. Chem Rev. 2009;109(2):259-302.

12. Guo Q, Shi S, Wang X, et al. Synthesis of a novel biodegradable poly(ester amine) (PEAs) copolymer based on low-molecular-weight polyethyleneimine for gene delivery. Int J Pharm. 2009;379(1):82-89.

13. Ko YT, Kale A, Hartner WC, Papahadjopoulos-Sternberg B, Torchilin VP. Self-assembling micelle-like nanoparticles based on phospholipidpolyethyleneimine conjugates for systemic gene delivery. J Control Release. 2009;133(2):132-138. 
14. Kabanov AV, Batrakova EV, Sriadibhatla S, Yang Z, Kelly DL, Alakov VY. Polymer genomics: shifting the gene and drug delivery paradigms. J Control Release. 2005;101(1-3):259-271.

15. Oh KT, Bronich TK, Kabanov AV. Micellar formulations for drug delivery based on mixtures of hydrophobic and hydrophilic Pluronic block copolymers. J Control Release. 2004;94(2-3):411-422.

16. Sahay G, Batrakova EV, Kabanov AV. Different internalization pathways of polymeric micelles and unimers and their effects on vesicular transport. Bioconjug Chem. 2008;19(10):2023-2029.

17. Kabanov AV, Batrakova EV, Alakhov VY. Pluronic block copolymers as novel polymer therapeutics for drug and gene delivery. $J$ Control Release. 2002;82(2-3):189-212.

18. Yin D, Ding X, Gao J, Chu C, Zou H, Gao S. Nonionic amphiphilic surfactant conjuncted polyethyleneimine as a new and highly efficient non-viral gene carrier. Macromol Res. 2009;17(1):19-25.

19. Piest M, Lin C, Mateos-Timoneda MA, et al. Novel poly(amido amine)s with bioreducible disulfide linkages in their diamino-units: structure effects and in vitro gene transfer properties. J Control Release. 2008; 130(1):38-45.

20. Tang GP, Guo HY, Alexis F, et al. Low molecular weight polyethylenimines linked by beta-cyclodextrin for gene transfer into the nervous system. J Gene Med. 2006;8(6):736-744.

21. Kim TH, Cook SE, Arote RB, et al. A degradable hyperbranched poly(ester amine) based on poloxamer diacrylate and polyethylenimine as a gene carrier. Macromol Biosci. 2007;7(5):611-619.

22. Arote R, Kim TH, Kim YK, et al. A biodegradable poly(ester amine) based on polycaprolactone and polyethylenimine as a gene carrier. Biomaterials. 2007;28(4):735-744.
23. Xu P, Quick GK, Yeo Y. Gene delivery through the use of a hyaluronate-associated intracellularly degradable crosslinked polyethyleneimine. Biomaterials. 2009;30(29):5834-5843.

24. Liang W, Gong H, Yin D, Lu S, Fu Q. High-molecular-weight polyethyleneimine conjuncted pluronic for gene transfer agents. Chem Pharm Bull (Tokyo). 2011;59(9):1094-1101.

25. Xu Z, Shen G, Xia X, et al. Comparisons of three polyethyleneiminederived nanoparticles as a gene therapy delivery system for renal cell carcinoma. J Transl Med. 2011;9(1):46.

26. Berthold PR, Shiraishi T, Nielsen PE. Cellular delivery and antisense effects of peptide nucleic acid conjugated to polyethyleneimine via disulfide linkers. Bioconjug Chem. 2010;21(10):1933-1938.

27. Roques C, Fattal E, Fromes Y. Comparison of toxicity and transfection efficiency of amphiphilic block copolymers and polycationic polymers in striated muscles. J Gene Med. 2009;11(3):240-249.

28. $\mathrm{Hu}$ X, Ji J. Covalent layer-by-layer assembly of hyperbranched polyether and polyethyleneimine: multilayer films providing possibilities for surface functionalization and local drug delivery. Biomacromolecules. 2011;12(12):4264-4271. Epub November 10, 2011.

29. Vinogradov SV, Kohli E, Zeman AD. Comparison of nanogel drug carriers and their formulations with nucleoside 5'-triphosphates. Pharm Res. 2006;23(5):920-930.

30. Xia T, Kovochich M, Liong M, et al. Polyethyleneimine coating enhances the cellular uptake of mesoporous silica nanoparticles and allows safe delivery of siRNA and DNA constructs. ACS Nano. 2009; 3(10):3273-3286.
International Journal of Nanomedicine

\section{Publish your work in this journal}

The International Journal of Nanomedicine is an international, peerreviewed journal focusing on the application of nanotechnology in diagnostics, therapeutics, and drug delivery systems throughout the biomedical field. This journal is indexed on PubMed Central, MedLine, CAS, SciSearch ${ }^{\circledR}$, Current Contents $₫ /$ Clinical Medicine,

\section{Dovepress}

Journal Citation Reports/Science Edition, EMBase, Scopus and the Elsevier Bibliographic databases. The manuscript management system is completely online and includes a very quick and fair peer-review system, which is all easy to use. Visit http://www.dovepress.com/ testimonials.php to read real quotes from published authors. 